\title{
Impact of proactive low-molecular weight heparin therapy on outcomes in COVID-19
}

\author{
Gormez $\mathrm{S}^{1}$, Gumusel $\mathrm{HK}^{2}$, Ekicibasi $\mathrm{E}^{3}$, Degirmencioglu A ${ }^{4}$, Paudel A $\mathrm{A}^{5}$, Akan $\mathrm{G}^{6}$, Atalar $\mathrm{F}^{7}$, \\ Erdim $R^{8}$, Eroglu $E^{9}$, Dagdelen $S^{9}$, Sariguzel $N^{10}$, Kirisoglu $\mathrm{CE}^{11}$, Pamukcu $\mathrm{B}^{12}$ \\ Acibadem Mehmet Ali Aydinlar University, Vocational School of Health Services, Department of First and Emergency Aid, \\ Acibadem Kozyatagi Hospital, Department of Cardiology, Istanbul, Turkey. burak.pamukcu@acibadem.edu.tr
}

\begin{abstract}
OBJECTIVES: Low molecular weight heparin (LMWH) may provide beneficial effects on outcomes of COVID-19. We aimed to examine the impact of LMWH treatment on clinical outcomes (duration of hospitalization, admission to intensive care unit, the requirement for mechanical ventilation, and death) of COVID-19 patients with normal D-dimer levels at admission.

BACKGROUND: Coronavirus disease-2019 (COVID-19) predisposes patients to arterial and venous thrombosis.

METHODS: In this retrospective, multicentre and observational study we analysed the data of 308 confirmed COVID-19 patients with normal D-dimer levels at initial admission. After propensity score matching (PSM) patients were grouped; Group 1; patients who received LMWH with D-dimer $\leq 0.5 \mathrm{mg} / \mathrm{L}$, Group 2; patients who received $\mathrm{LMWH}$ after D-dimer levels exceeded $0.5 \mathrm{mg} / \mathrm{L}$, and Group 3; patients who did not receive LMWH.

RESULTS: After PSM, each group comprised 40 patients. The patients in Group1 had the best clinical outcomes compared to the other groups. Group 3 had the worst clinical outcomes $(p<0.005)$. The benefit of LMWH increased with early prophylactic therapy especially when started while the D-dimer levels were $\leq 0.5 \mathrm{mg} / \mathrm{L}$. CONCLUSION: Our results strongly suggest that proactive LMWH therapy improves clinical outcomes in hospitalized COVID-19 patients even with normal D-dimer levels $(\leq 0.5 \mathrm{mg} / \mathrm{L})$ (Tab. 3, Fig. 2, Ref. 34). Text in PDF www.elis.sk

KEY WORDS: COVID-19; SARS-CoV-2; thrombosis; antithrombotic therapy; low-molecular-weight heparin; D-dimer; enoxaparin.
\end{abstract}

\begin{abstract}
${ }^{1}$ Acibadem Mehmet Ali Aydinlar University, Faculty of Medicine, Department of Cardiology, Acibadem Kadikoy Hospital, Istanbul, Turkey, ${ }^{2}$ Acibadem, Kadikoy Hospital, Department of Cardiology, Istanbul, Turkey, ${ }^{3}$ Acibadem Mehmet Ali Aydinlar University, Vocational School of Health Services, Acibadem Altunizade Hospital, Department of Cardiology, Istanbul, Turkey, ${ }^{4}$ Acibadem Mehmet Ali Aydinlar University, Faculty of Medicine, Department of Cardiology, Acibadem Maslak Hospital, Istanbul, Turkey, ${ }^{5}$ Acibadem Altunizade Hospital, Department of Cardiology, Istanbul, Turkey, ${ }^{6}$ Muhimbili University of Health and Allied Sciences, Department of Biochemistry, MUHAS Genetics Laboratory, Dar es Salaam, Tanzania, ${ }^{7}$ Istanbul University, Child Health Institute, Department of Family Health, Istanbul, Turkey, ${ }^{8}$ Acibadem Mehmet Ali Aydinlar University, Vocational School of Health Services, Acibadem Kadikoy Hospital, Department of Cardiology, Istanbul, Turkey, ${ }^{9}$ Acibadem Mehmet Ali Aydinlar University, Faculty of Medicine, Department of Cardiology, Acibadem Altunizade Hospital, Istanbul, Turkey, ${ }^{10}$ Acibadem Kadikoy \& Kozyatagi Hospitals, Department of Infection Diseases Istanbul, Turkey, ${ }^{11}$ Acibadem Mehmet Ali Aydinlar University, Faculty of Medicine, Department of Chest Diseases and Tuberculosis, Acibadem Kozyatagi Hospital, Istanbul, Turkey, and ${ }^{12}$ Acibadem Mehmet Ali Aydinlar University, Vocational School of Health Services, Department of First and Emergency Aid, Acibadem Kozyatagi Hospital, Department of Cardiology, Istanbul, Turkey
\end{abstract}

Address for correspondence: B. Pamukcu, MD, Prof, Acibadem Kozyatagi Hastanesi, Kardiyoloji Bolumu, Inonu Caddesi Okur Sk. No: 20, 34742, Kadikoy, Istanbul, Turkey.

Phone: +90.216 .5714449 , Fax: +90.216 .5714000$

\section{Introduction}

The coronavirus disease-2019 (COVID-19) pandemic initially emerged as an outbreak of pneumonia with an unknown aetiology in Wuhan, China, in late December 2019. The Chinese scientists identified the causative agent in January 2020, a new enveloped ribonucleic acid betacoronavirus which is genetically similar to severe acute respiratory syndrome (SARS)-like corona viruses originated in bats and called 2019-nCov $(1,2)$. The World Health Organization (WHO) designated the virus as severe acute respiratory syndrome corona virus-2 (SARS-CoV-2) and the associated disease as COVID-19, declared the pandemic that spread to all continents shortly after it appeared in China. The SARS-CoV-2 infection, with its particularly pulmonary and other systemic involvement, is associated with significant morbidity and mortality, leading to hundreds of thousands of deaths worldwide $(3,4)$.

Although the exact mechanism is unknown, recent studies have reported that patients with severe COVID-19 requiring mechanical ventilation (MV), intensive care unit (ICU) admission, or experiencing death were at the same time patients who had the highest thrombotic events and haemostatic abnormalities from 


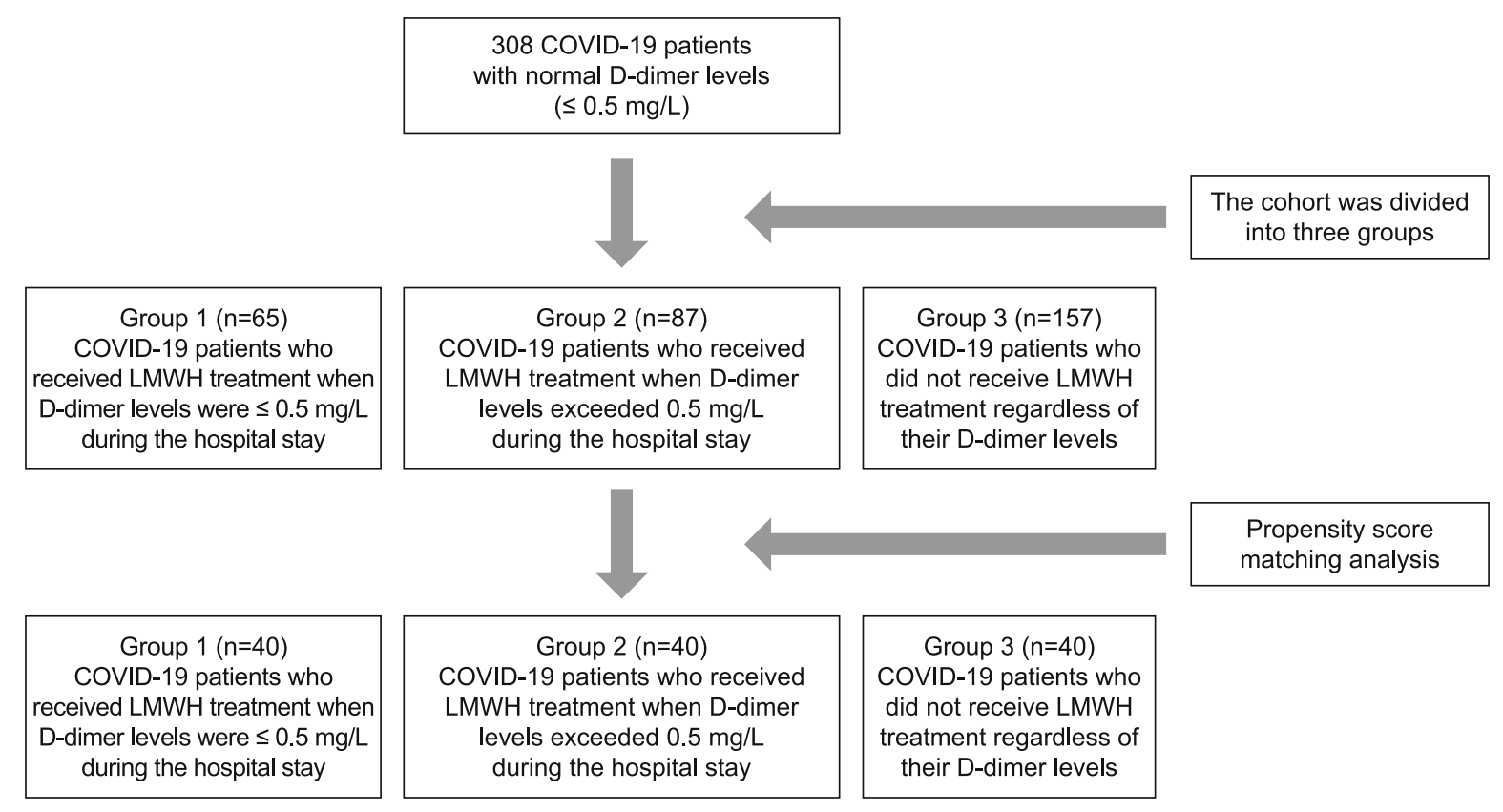

Fig. 1. Summary of the study design.

mild thrombocytopenia to increased D-dimer, fibrinogen, and fibrin degradation products (FDPs) levels (5-12). Of note, COVID-19 may predispose to both venous and arterial thromboembolism due to excessive vascular and systemic inflammation, endothelial dysfunction, cytokine storm, hypoxia, and immobilization $(13,14)$. Thrombosis is frequently seen in the majority of patients having obesity, cardiovascular diseases, and common medical comorbidities such as hypertension and diabetes mellitus $(15,16)$.

The International Society on Thrombosis and Haemostasis (ISTH) recommended a prophylactic dose of low-molecular-weight heparin (LMWH) to all hospitalized patients with COVID-19, unless it is contraindicated (17). Furthermore, individualized anticoagulant therapy is encouraged in patients with COVID-19 (17). Thus, clinicians depending on their individual experience use various prophylactic, intermediate or therapeutic anticoagulant doses based on the patient's clinical situation. However, no exact protocol of anticoagulant therapy and optimal regimen has been established yet, for the majority of COVID-19 patients.

In the present study, we hypothesized that early prophylactic administration of LMWH therapy might have positive effects on clinical and prognostic laboratory parameters in COVID-19 patients without a bleeding risk, even in the presence of normal D-dimer levels $(<0.5 \mathrm{mg} / \mathrm{L})$ at the time of initial admission. We, therefore, aimed to evaluate the impact of LMWH therapy on clinical outcomes in COVID-19 described as duration of hospitalization, admission to ICU, requirement for MV, and death. We have also assessed the effect of LMWH therapy started at different levels of D-dimer i.e., normal $(<0.5 \mathrm{mg} / \mathrm{L})$ and increased levels $(>0.5 \mathrm{mg} / \mathrm{L})$ on recently defined prognostic laboratory parameters including D-dimer, ferritin, C-reactive protein (CRP), neutrophilto-lymphocyte ratio (NLR) and platelet count.

\section{Materials and methods}

\section{Study design and study population}

This retrospective, multi-centre, observational study was conducted at four hospitals of Acibadem Healthcare Group (Istanbul, Turkey). This study was designed to assess whether early prophylactic administration of LMWH therapy might have positive effects on COVID-19 outcomes. Inclusion criteria were as follows: age $\geq 18$ years, having COVID-19-associated respiratory tract infection (pneumonia), having plasma D-dimer levels $\leq 0.5 \mathrm{mg} / \mathrm{L}$ at the time of initial admission, and presence of dyspnoea and/or decreased oxygen saturation. Exclusion criteria were as follows: age $<18$ years, missing medical data, having elevated plasma D-dimer levels ( $>0.5 \mathrm{mg} / \mathrm{L})$ at the time of initial admission, being pregnanant or active bleeding. The diagnosis of COVID-19 was made according to the WHO interim guidance (18) and confirmed by RT-PCR detection of the SARS-CoV-2 in the Republic of Turkey, Ministry of Health clinical laboratory. After fulfilling inclusion and exclusion criteria a total of 308 adult patients with confirmed COVID-19 and plasma D-dimer levels $\leq 0.5 \mathrm{mg} / \mathrm{L}$ at the time of initial admission were retrospectively screened.

To investigate the effect of LMWH therapy on COVID-19 clinical outcomes we sub-grouped 308 COVID-19 patients according to LMWH therapy. Group 1 consisted of patients who received LMWH treatment at normal D-dimer levels $(\leq 0.5 \mathrm{mg} / \mathrm{L})$, $(\mathrm{n}=64)$ during hospitalization (LMWH with low D-dimer). Group 2 consisted of patients who received LMWH treatment at elevated D-dimer levels $(>0.5 \mathrm{mg} / \mathrm{L}),(\mathrm{n}=87)$ during hospitalization (LMWH with elevated D-dimer). Finally, Group 3 consisted of patients who did not receive LMWH treatment at all regardless of their D-dimer levels $(n=157)$, (No LMWH). 
582-589

To minimize the effects of confounding factors, propensity score-matching (PSM) analyses were done, and three groups were created as described above. Figure 1 summarizes the study design and grouping of patients.

Group 1 and Group 2 patients received enoxaparin as the only available LMWH in the local market. The dosage was calculated according to the bodyweight of each individual patient. The patients with D-dimer levels between 0.5 and $3 \mathrm{mg} / \mathrm{L}$ received $1 \mathrm{mg} / \mathrm{kg}$ once daily, while the patients with D-dimer levels of $>3 \mathrm{mg} / \mathrm{L}$ received $1 \mathrm{mg} / \mathrm{kg}$ twice daily.

In the present study, tachypnoea (respiratory rate $>30 / \mathrm{mi}$ nutes), $\mathrm{SpO}_{2}<90 \%$ or $<70 \mathrm{mmHg}$ (in room air without response to nasal oxygen up to $12 \mathrm{~L}$ /minutes with reservoir), progressive dyspnoea and increased work of breathing, lactate levels of $>2$ $\mathrm{mmol} / \mathrm{L}$, hypotension (systolic blood pressure $<90 \mathrm{mmHg},>40$ $\mathrm{mmHg}$ drop from initial blood pressure, mean arterial pressure $<65 \mathrm{mmHg}$ ), organ dysfunction (confusion, renal failure, liver dysfunction, elevated troponin I) were accepted as criteria for therapy in intensive care unit.

The study protocol was approved by the institutional Ethics Committee (ATADEK-2020-09/3) and local government health authority (2020-05-11T12_01_54). The study was conducted in accordance with the principles of the Declaration of Helsinki.

\section{Data collection}

Demographic and clinical characteristics of the patients including age and sex, medical history, cigarette use, current medications, comorbidities such as hypertension, diabetes mellitus, coronary artery disease (CAD), chronic respiratory disease (CRD) or chronic kidney disease (CKD), clinical symptoms such as fever, cough, dyspnoea or sore throat, laboratory parameters such as haemoglobin, platelet count, CRP, ferritin, D-dimer and creatinine, imaging study findings including chest X-ray or thoracic computed tomography (CT) were collected and analysed in a common electronic medical system designed for all participating centres. Data including clinical outcomes were obtained from the electronic database system and confirmed by chest diseases and infectious diseases departments. The duration of hospitalization, admission to the ICU, requirement for $\mathrm{MV}$, and clinical events (i.e., thrombotic or haemorrhagic) were recorded. Bleeding was classified according to the ISTH criteria (19).

\section{Laboratory assays and interventions}

Blood samples were collected within $24 \mathrm{~h}$ after admission to perform routine laboratory tests including complete blood count, coagulation tests and serum biochemical tests in the hospital setting. The D-dimer levels were measured using the Sysmex CA660 (Sysmex Corp., IL, USA) by the immune turbidimetric assay via the Siemens Innovance D-dimer kits (Siemens Healthineers, PA, USA). Inter and intra-day variability coefficients were calculated as $3.41 \%$ and $4.22 \%$, respectively. The laboratory normal reference range for D-dimer was 0 to 0.5 $\mathrm{mg} / \mathrm{mL}$. The D-dimer levels were expressed in $\mu \mathrm{g} / \mathrm{mL}$ FEU (i.e., fibrinogen equivalent unit). Serum electrolyte levels, ferritin, $\mathrm{CRP}$, and troponin I measurements were done using standar- dized methods. All measurements were carried out within $2 \mathrm{~h}$ after blood sampling.

\section{Propensity score-matched analysis}

PSM analysis venture to compare outcomes of treatment between patients' subgroups which have a similar distribution of all the measured covariates. Bias is inevitable in observational research, leading to raggedly distributed confounding factors between study groups. PSM analysis is the probability analysis of the condition of assignment to a particular treatment given a set of observed covariates $(20,21)$. Therefore, PSM was utilized in our research to minimize selection bias and imbalanced distributions of the confounding factors.

In our study, a one-to-one nearest neighbour propensity score matching algorithm with $\pm 1 \%$ caliper was applied to a multinomial logistic regression model for LMWH therapy group propensity in order to identify a sample of clinically-similar patients with balanced confounding covariates across the three groups.

For calculation of the propensity score, baseline covariates were included as confounders in a multivariable logistic regression model to predict the treatment of interest without including the outcome. The cofounders included were age, gender, symptoms of COVID-19 (fever, cough, dyspnoea), comorbidities (diabetes mellitus, hypertension, hyperlipidaemia, CRD, CKD, CAD, obesity and history of cancer), and basal laboratory parameters (D-Dimer, CRP, Ferritin, NLR, and Troponin I).

To this end, the total sample size of PSM for each group was as follows: 40 patients in Group 1 (LMWH with low D-dimer), 40 patients in Group 2 (LMWH with elevated D-dimer) and 40 patients in Group 3 (No LMWH).

\section{Statistical analysis}

Statistical analysis was performed using the Statistical Package for the Social Sciences (SPSS) version 25.0 statistical software (IBM Corp., Armonk, NY, USA). PSM analysis was performed using SAS version 9.4 (SAS Institute Inc., Cary, NC). All figures were generated using the GraphPad Prism version 8.0 (GraphPad Software Inc., San Diego, CA, USA). Descriptive data were expressed as mean \pm standard deviation (SD), median (min-max) or number and frequency, where applicable. Student's t-test and Mann-Whitney U test were used to compare two groups with regards to normal and non-normal distributed quantitative variables, respectively. Categorical variables were compared using the chi-square $(\chi 2)$ test. One-way analysis of variance (ANOVA) (and post-hoc Bonferroni tests) and Kruskal-Wallis nonparametric ANOVA were used to compare the groups with regards to normal and non-normal distributed quantitative variables, respectively. Logistic regression was then used to compare binary categorical outcomes between propensity matched groups. A p value of $<0.05$ was considered statistically significant.

\section{Results}

Of all the study population, 114 were females and 194 were males with a median age of 51 (range: 71,18 to 89 ) years. The most 


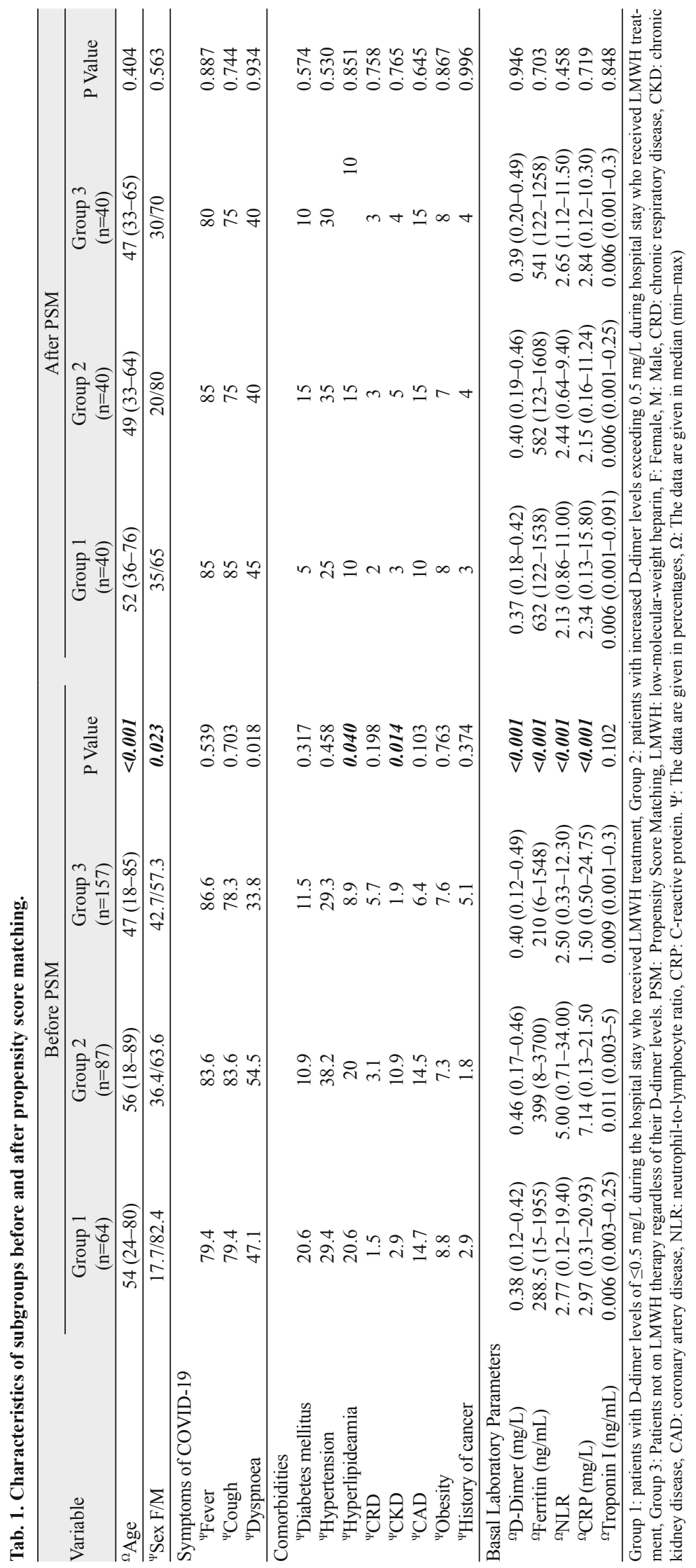

common symptoms were fever and cough ( $84 \%$ and $79.8 \%$, respectively). One hundred fifteen $(44.7 \%)$ patients had one or more chronic underlying diseases including hypertension, diabetes mellitus, CAD, obesity, cancer, and CRD.

We divided our study population into three groups according to LMWH therapy; Group 1: patients received LMWH treatment when D-dimer levels were $\leq 0.5 \mathrm{mg} / \mathrm{L}$ during the hospital stay ( $\mathrm{n}$ =65), Group 2: patients received LMWH treatment when D-dimer levels exceeded $0.5 \mathrm{mg} / \mathrm{L}$ during the hospital stay $(\mathrm{n}=87)$, and Group 3: patients did not receive LMWH treatment regardless of their D-dimer levels $(n=157)$.

After applying our groups in PSM for appropriately balancing confounding covariates across and each group was comprised of 40 patients (Table 1, "After Propensity Matching" all respective $\mathrm{p}>$ 0.1 ). Despite the significant differences in certain variables (such as age, sex, basal laboratory parameters), no significant differences were observed in age $(p=0.404)$, sex $(p=0.563)$, D-Dimer level $(p=$ $0.946)$, ferritin level ( $p=0.703)$, CRP level $(\mathrm{p}=$ $0.719)$ and NLR $(p=0.458)$ after propensity score matching (Tab. 1).

From the PSM groups, medications in-hospital treatment, the clinical outcomes and prognostic laboratory parameters in the three groups are presented in Tables 2 and 3.

Three groups were similarly distributed in terms of antiviral drugs, and antibiotics which were given for COVID-19 treatment during their hospital stay. Also, there was no significant difference among the groups regarding antithrombotic medications that the patients were already receiving (Tab. 2).

Furthermore, the clinical outcomes and prognostic laboratory parameters of the propensity score matched groups are summarized in Table 3. Accordingly, one patient in each group experienced venous thromboembolism (VTE), while one patient in Group 2 and one patient in Group 3 had minor bleeding (epistaxis and haemoptysis) according to the ISTH criteria (19).

We observed significant differences in the prognostic laboratory parameters, length of hospital stays, length of ICU therapy and requirement for MV among the groups ( $p<0.05$ for all). The COVID-19 patients who were not receiving LMWH therapy (Group 3) required more MV (55\%) and admission to ICU $(60 \%)$ compared to other matched groups ( $p<0.05$ respectively) (Fig. 2).

A total of three patients (one in each subgroup) died from COVID-19, indicating no statistically significant difference in the mortality rate among the groups. 
Tab. 2. Medications in-hospital treatment.

\begin{tabular}{lcccc}
\hline Variable & $\begin{array}{c}\text { Group 1 } \\
(\mathrm{n}=40)\end{array}$ & $\begin{array}{c}\text { Group2 } \\
(\mathrm{n}=40)\end{array}$ & $\begin{array}{c}\text { Group 3 } \\
(\mathrm{n}=40)\end{array}$ & $\mathrm{p}$ \\
\hline $\begin{array}{l}\text { Use of co-medications } \\
\quad \text { Acetylsalicylic acid }\end{array}$ & 7 & 11 & 5 & 0.60 \\
$\quad$ Clopidogrel & 0 & 1 & 1 & 0.57 \\
\hline $\begin{array}{l}\text { In-hospital treatment } \\
\text { Azithromycin }\end{array}$ & 14 & 16 & 22 & 0.577 \\
$\quad$ Hydroxychloroquine & 32 & 38 & 40 & 0.565 \\
Oseltamivir & 18 & 26 & 32 & 0.08 \\
\hline
\end{tabular}

Group 1: patients with D-dimer levels of $\leq 0.5 \mathrm{mg} / \mathrm{L}$ during the hospital stay who received LMWH treatment, Group 2: patients with increased D-dimer levels exceeding $0.5 \mathrm{mg} / \mathrm{L}$ during hospital stay who received LMWH treatment, Group 3: Patients not on LMWH therapy regardless of their D-dimer levels. The values are calculated using the chi-square test and the data are given in percentages. Statistical significance at $\mathrm{p}<0.05$.

There were statistically significant differences in terms of peak serum levels of D-dimer, ferritin, CRP, and NLR among the matched groups $(\mathrm{p}<0.05$ respectively). The median peak D-Dimer levels were $1.4 \mathrm{mg} / \mathrm{L}(0.27-2.68)$ in Group 1, while the median peak D-Dimer levels were $3.87 \mathrm{mg} / \mathrm{L}$ (1.19-8.4) in Group 2 and it was $8.1 \mathrm{mg} / \mathrm{L}(2.31-1.72)$ in Group 3. The peak serum levels of ferritin, CRP, and NLR were also statistically significant among the propensity score matched groups (Tab. 3).

Our results showed that LMWH therapy may improve clinical progress and reduce the need for therapy in the ICU and requirement for MV, particularly when started before D-dimer levels increased and exceeded $0.5 \mathrm{mg} / \mathrm{L}$ (Group 1).

\section{Discussion}

In the present study, we determined that COVID-19 patients who were treated with LMWH, as soon as possible after hospitalization and especially before D-dimer levels were increased and exceeded $0.5 \mathrm{mg} / \mathrm{L}$, had the best clinical outcomes and favourable prognostic laboratory parameter levels, compared to those who received the LMWH therapy when D-dimer levels increased and exceeded the threshold of $0.5 \mathrm{mg} / \mathrm{L}$ during hospitalization and also patients who never received LMWH. The latter COVID-19 patients had the worst clinical outcomes. Our results indicate that the benefit from therapy appears to be increased with the early administration of LMWH therapy, before D-dimer levels exceed the threshold of $0.5 \mathrm{mg} / \mathrm{L}$.

Tab. 3. Clinical outcomes and prognostic laboratory parameters of the patients.

\begin{tabular}{|c|c|c|c|c|c|}
\hline Variable & & $\begin{array}{c}\text { Group } 1 \\
(\mathrm{n}=40)\end{array}$ & $\begin{array}{c}\text { Group } 2 \\
(\mathrm{n}=40)\end{array}$ & $\begin{array}{c}\text { Group } 3 \\
(\mathrm{n}=40)\end{array}$ & $\mathrm{p}$ \\
\hline \multicolumn{6}{|l|}{ Clinical outcomes } \\
\hline${ }^{\Psi}$ Length of hospital stay (days) & & $7(1-40)$ & $15(7-45)$ & $21(16-55)$ & $\begin{array}{r}r 0.001 \\
\times 0.001 \\
\times 0.006 \\
0.001\end{array}$ \\
\hline${ }^{\Psi}$ Length of ICU stay (days) & & $1(0-30)$ & $2(0-45)$ & $17(5-50)$ & $\begin{array}{r}80.421 \\
\times 0.001 \\
{ }^{8} 0.009\end{array}$ \\
\hline${ }^{\Omega} \mathrm{Admission}$ to ICU & & $10(25)$ & $18(45)$ & $24(60)$ & 0.001 \\
\hline${ }^{\Omega}$ Requirement for MV & & $4(10)$ & $16(40)$ & $22(55)$ & 0.003 \\
\hline${ }^{\Omega}$ Death & & $1(2.5)$ & $1(2.5)$ & $1(2.5)$ & 0.996 \\
\hline${ }^{\Omega}$ In-hospital thromboembolic event & & $1(33.3)$ & $1(33.3)$ & $1(33.3)$ & 0.946 \\
\hline${ }^{\Omega}$ Minor bleeding & & $0(0$ & $1(1.9)$ & $1(1.4)$ & 0.964 \\
\hline${ }^{\Omega}$ Major bleeding & & $0(0)$ & $0(0)$ & $0(0)$ & - \\
\hline \multicolumn{6}{|l|}{$\begin{array}{l}\text { Prognostic Laboratory Parameters } \\
\text { Normal Range }\end{array}$} \\
\hline${ }^{\Psi}$ Peak D-dimer (mg/L) & $<0.5$ & $1.4(0.27-2.68)$ & $3.87(1.19-8.4)$ & $8.1(2.31-21.72)$ & $\begin{array}{r}r 0.039 \\
\times 0.001 \\
\times 0.001\end{array}$ \\
\hline${ }^{\Psi}$ Peak ferritin (ng/mL) & $22-322$ & $529(8-1891)$ & $1090(124-3881)$ & $1808(1117-3444)$ & $\begin{array}{r}0.019 \\
\times 0.001 \\
0.045 \\
\end{array}$ \\
\hline${ }^{\Psi}$ Peak NLR & $<3.13$ & $2.63(1.14-8.50)$ & $8.29(2.21-11.00)$ & $12.85(1.68-24)$ & $\begin{array}{l}0.012 \\
\times 0.001 \\
0.004 \\
\end{array}$ \\
\hline${ }^{\Psi}$ Peak CRP (mg/L) & $<0.5$ & $5.56(1.5-10.72)$ & $12.38(4-29.84)$ & $17.92(9.54-31.64)$ & $\begin{array}{r}0.001 \\
\times 0.001 \\
{ }^{x} 0.005 \\
\end{array}$ \\
\hline${ }^{\Psi}$ Peak troponin I (ng/mL) & $<0.04$ & $0.006(0.005-0.091)$ & $0.006(0.006-0.092)$ & $0.009(0.006-0.986)$ & 0.113 \\
\hline
\end{tabular}



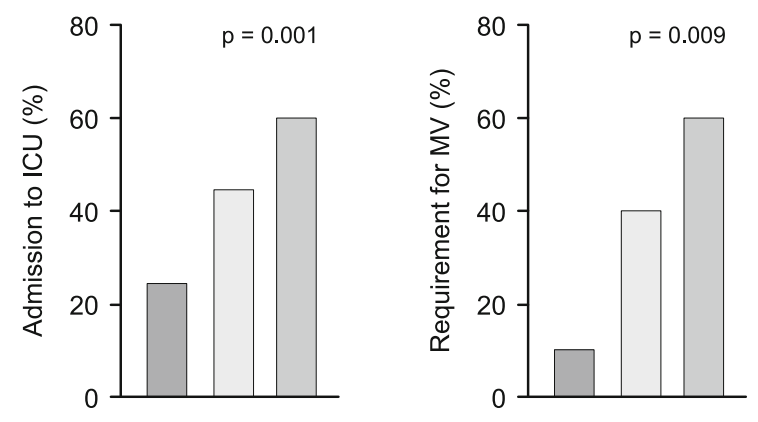

$\square$ Group $1 \square$ Group $2 \square$ Group 3

Fig. 2. Admission to ICU and requirement for MV of the study groups. Group 1: Patients with D-dimer levels of $\leq 0.5 \mathrm{mg} / \mathrm{L}$ during the hospital stay receiving LMWH treatment, Group 2: Patients with increased D-dimer levels exceeding $0.5 \mathrm{mg} / \mathrm{L}$ during hospital stay receiving LMWH treatment, Group 3: Patients not on LMWH therapy regardless of their D-dimer levels. Abbreviations: ICU: Intensive care unit, MV: Mechanical ventilation.

Recent studies established the presence of a thrombotic and inflammatory state in patients with SARS-CoV-2 infection, particularly in those who are clinically classified as severe or critically ill (22). The underlying mechanisms of this thrombotic state include excessive inflammation, platelet activation, endothelial dysfunction, and stasis (12). The COVID-19-associated coagulation abnormalities comprise elevated D-dimer levels, modestly decreased platelet counts, prolonged prothrombin time, and disseminated intravascular coagulation (DIC). Thrombotic clinical events including venous and/or arterial thrombosis and peripheral thrombotic microangiopathy-associated skin lesions are very common (17, 23-26). However, it still remains unclear whether thromboembolic events depend on the infection itself or inflammationdriven cytokine storm. Increased D-dimer levels are frequently reported in patients with COVID-19 and are strongly associated with prognosis (27). In a recent study, the deceased and survived COVID-19 patients were compared and a 3.5-fold increase in D-dimer and 1.9-fold increase in the FDPs were observed (23). In addition, $71.4 \%$ of non-survivors had DIC compared to $0.6 \%$ among survivors (23). Another study suggested that patients with COVID-19 who had increased D-dimer levels might benefit from anticoagulant treatment (14). In our study, all the patients included had D-dimer levels $<0.5 \mathrm{mg} / \mathrm{L}$ at the time of initial admission. Among them, the patients who never received LMWH developed more severe clinical disease and required more admissions to ICU and MV. However, we observed no statistically significant difference in terms of mortality among the groups. Since the association between thrombosis and COVID-19 prognosis was not understood well at the beginning of the pandemic, there was no recommendation for anticoagulant therapy and therefore patients in Group 3 did not receive LMWH therapy regardless of their D-dimer levels.

Local thrombosis in pulmonary vessels but not embolism appears to be associated with poor prognosis in COVID-19. For instance, venous thrombosis is frequently reported in patients with COVID-19. A recent autopsy study of COVID-19 patients established thrombotic lesions in small- and mid-sized pulmonary arteries in various degrees in all 11 patients and was reported to be associated with infarction in eight patients and bronchopneumonia in six patients (28). Based on these findings, the authors proposed thrombotic pulmonary lesions as the main cause of death and, more importantly, they concluded that the lesions were caused by thrombosis rather than by thromboembolism, since they observed that most vessels were completely occluded by a thrombus and small arteries $(<1 \mathrm{~mm}$ in diameter) were involved (28). These data support the association between thrombosis and COVID-19 prognosis. Another recent study performed thromboelastography in 24 COVID-19 patients who were under treatment in the ICU and reported a state of hypercoagulability, but not DIC (29). In this study, the authors documented that there was a hypercoagulable and severe inflammatory state which might explain venous thromboembolic events. Assessment of VTE by complete Duplex ultrasound in 26 anticoagulated COVID-19 patients treated in the ICU indicated an overall incidence of VTE of $69 \%$, despite the administration of prophylactic or therapeutic doses of anticoagulants (30). In our study, we evaluated clinically the presence of thrombotic events and we found that three patients had venous thrombosis (two upper extremity peripheral venous thrombosis and one lower extremity deep vein thrombosis).

In COVID-19, there is also an increased risk of arterial thrombosis. Peripheral arterial thrombosis was reported in critically ill COVID-19 patients (31). Furthermore, in some cases, myocardial infarction was reported, while troponin levels were frequently found to increase due to myocarditis (32). In our study, none of the patients developed clinically prominent arterial thrombosis and no ST elevation myocardial infarction or dynamic electrocardiographic changes were observed.

In the present study, we found better clinical outcomes among patients who received LMWH therapy with a D-dimer levels of $<0.5 \mathrm{mg} / \mathrm{L}$ (Group 1). Recent studies reported controversial results and recommendations on anticoagulation doses. A retrospective, observational cohort study showed that treatment-dose systemic anticoagulation improved the mortality rates among COVID-19 patients requiring mechanical ventilation $(29.1 \%$ vs $62.7 \%$, mortality rates of anticoagulated and non-anticoagulated patients, respectively) (33). However, in the overall comparison, the authors reported no statistically significant difference in the mortality rates among patients who received anticoagulation and who did $\operatorname{not}(22.5 \%$ vs $22.8 \%$, respectively) (33). The use of therapeutic doses of anticoagulants, rather than prophylactic doses, is controversial, since there is no prospective, randomized-controlled study yet. Nonetheless, some of the experts suggest that high-dose heparin in COVID-19 may not only be ineffective, but it may be also dangerous. Anticoagulation with higher doses of heparin may contribute to the haemorrhagic component of microangiopathy, since there is some evidence indicating an increased incidence of major and fatal bleeding with high-dose LMWH therapy in COVID-19 patients (34).

In our study, COVID-19 patients who did not receive LMWH therapy were at an increased risk of poor clinical outcomes such 
as prolonged hospitalization, increased ICU admission, and more MV. However, we found no significant increase in thromboembolic events and mortality in patients who never received LMWH, compared to those in the other matched groups.

Nonetheless, this study has some limitations. In our opinion, if we could evaluate all the patients with imaging modalities, thus more asymptomatic thrombotic events might have been detected, particularly in Group 3. The presence of asymptomatic thrombotic events could explain, in part, why clinical outcomes were better in Group 1 and 2 than in patients who were not receiving LMWH at all, despite no shown difference in terms of clinical thromboembolic events. We think that this hypothesis can be further assessed in another study with prospective design.

Our study has a retrospective design with a relatively small sample size which may have caused a bias in the results. Therefore, we recommend further large-scale, prospective studies to draw a definitive conclusion. On the other hand, to the best of our knowledge, our study is the first study which showed the beneficial effects of prophylactic LMWH therapy in hospitalized COVID-19 patients with normal initial D-dimer levels. Our findings provide evidence to clinical practice and support the recommendations of the ISTH, in terms of LMWH therapy in all hospitalized patients, even in non-critically ill patients and at least at the prophylactic doses (17).

\section{Learning points}

- The patients who received low-molecular-weight heparin (LMWH) before D-dimer levels exceeded $0.5 \mathrm{mg} / \mathrm{L}$ had better clinical outcomes compared to patients who received LMWH after D-dimer levels exceeded $0.5 \mathrm{mg} / \mathrm{L}$ and patients who did not receive LMWH at all during in hospital treatment.

- Early and proactive administration of LMWH therapy improved clinical outcomes even in patients with normal D-dimer levels at initial admission to the hospital.

- COVID-19 patients who never received LMWH therapy required prolonged hospitalization, experienced worst clinical outcomes including more intensive care unit admission, and mechanical ventilation.

\section{Conclusions}

In conclusion, our study showed that clinical outcomes in COVID-19 patients were strongly associated with markers of thrombosis (i.e., D-dimer) and proactive administration of LMWH at appropriate doses when the D-dimer levels were $<0.5 \mathrm{mg} / \mathrm{L} \mathrm{im}$ proved clinical outcomes. In addition, COVID-19 patients who did not receive antithrombotic therapy were at an increased risk of poor clinical outcomes. Based on these results, in hospitalized COVID-19 patients, even with normal D-dimer levels, proactive LMWH therapy can provide clinical benefit and should be considered. We believe that the possible mechanisms leading to increased thrombosis should be investigated further and randomized, prospective, and controlled clinical trials are needed to establish the optimal timing and dosing of antithrombotic therapy and also to exclude all bias and confounders.

\section{References}

1. Zhu N, Zhang D, Wang W, Li X, Yang B, Song J, Zhao X, Huang B, Shi W, Lu R, Niu P, Zhan F, Ma X, Wang D, Xu W, Wu G, Gao GF, Tan W, China Novel Coronavirus Investigating and Research Team. A Novel Coronavirus from Patients with Pneumonia in China, 2019. N Engl J Med 2020; 382 (8): 727-733.

2. Lu R, Zhao X, Li J, Niu P, Yang B, Wu H, Wang W, Song H, Huang B, Zhu B, Bi Y, Ma X, Zhan F, Wang L, Hu T, Zhou H, Hu Z, Zhou W, Zhao L, Chen J, Meng Y, Wang J, Lin Y, Yuan J, Xie Z, Ma J, Liu WJ, Wang D, Xu W, Holmes EC, Gao GF, Wu G, Chen W, Shi W, Tan W. Genomic characterization and epidemiology of 2019 novel coronavirus: implication for virus origins and receptor binding. Lancet 2020; 395: 565-574.

3. Vermeiren C, Marchand-Senécal X, Sheldrake E, Bulir D, Smieja M, Chong S, Forbes JD, Katz K. Comparison of Copan Eswab and FLOQswab for COVID-19 PCR Diagnosis: Working Around a Supply Shortage. J Clin Microbiol 2020 Apr 15; JCM.00669-20.

4. Lai CC, Shih TP, Ko WC, Tang HJ, Hsueh PR. Severe acute respiratory syndrome coronavirus 2 (SARS-CoV-2) and coronavirus disease-2019 (COVID-19): The epidemic and the challenges.Int J Antimicrob Agents 2020 Mar; 55(3): 105924. DOI: 10.1016/j.ijantimicag.2020.105924.

5. Connors JM, Levy JH. COVID-19 and its implications for thrombosis and anticoagulation. Blood 2020 27: blood.2020006000. DOI: 10.1182/ blood.2020006000.

6. Chen N, Zhou M, Dong X, Qu J, Gong F, Han Y, Qiu Y, Wang J, Liu Y, Wei Y, Xia J, Yu T, Zhang X, Zhang L. Epidemiological and clinical characteristics of 99 cases of 2019 novel coronavirus pneumonia in Wuhan, China: a descriptive study. Lancet 2020; 395 (10223): 507-513.

7. Huang C, Wang Y, Li X, Ren L, Zhao J, Hu Y, Zhang L, Fan G, Xu J, Gu X, Cheng Z, Yu T, Xia J, Wei Y, Wu W, Xie X, Yin W, Li H, Liu M, Xiao Y, Gao H, Guo L, Xie J, Wang G, Jiang R, Gao Z, Jin Q, Wang J, Cao B. Clinical features of patients infected with 2019 novel coronavirus in Wuhan, China. Lancet 2020; 395 (10223): 497-506.

8. Lippi G, Plebani M, Michael Henry B. Thrombocytopenia is associated with severe coronavirus disease 2019 (COVID-19) infections: A meta-analysis. Clin Chim Acta 2020; 506: 145-148.

9. Lippi G, Favaloro EJ. D-dimer is associated with severity of coronavirus disease 2019 (COVID-19): a pooled analysis. Thromb Haemost 2020; 120 (5): 876-878.

10. Lillicrap D. Disseminated intravascular coagulation in patients with 2019-nCoV. pneumonia. J Thromb Haemost 2020; 18 (4): 786-787.

11. Zhang Y, Xiao M, Zhang S, Xia P, Cao W, Jiang W, Chen H, Ding X, Zhao H, Zhang H, Wang C, Zhao J, Sun X, Tian R, Wu W, Wu D, Ma J, Chen Y, Zhang D, Xie J, Yan X, Zhou X, Liu Z, Wang J, Du B, Qin Y, Gao P, Qin X, Xu Y, Zhang W, Li T, Zhang F, Zhao Y, Li Y, Zhang S. Coagulopathy and Antiphospholipid Antibodies in Patients with CoVID-19. N Engl J Med 2020; 382 (17): e38.

12. Bikdeli B, Madhavan MV, Jimenez D, Chuich T, Dreyfus I, Driggin E, Der Nigoghossian C, Ageno W, Madjid M, Guo Y, Tang LV, Hu Y, Giri J, Cushman M, Quéré I, Dimakakos EP, Gibson M, Lippi G, Favaloro EJ, Fareed J, Caprini JA, Tafur AJ, Burton JR, Francese DP, Wang EY, Falanga A, McLintock C, Hunt BJ, Spyropoulos AC, Barnes GD, Eikelboom JW, Weinberg I, Schulman S, Carrier M, Piazza G, Beckman JA, Steg PG, Stone GW, Rosenkranz S, Goldhaber SZ, Parikh SA, Monreal M, Krumholz HM, Konstantinides SV, Weitz JI, Lip GYH. COVID-19 and Thrombotic or Thromboembolic Disease: 
Implications for Prevention, Antithrombotic Therapy, and Follow-up. J Amer Coll Cardiol 2020; S0735-1097 (20)35008-7. DOI: 10.1016/j. jacc.2020.04.031.

13. Yin S, Huang M, Li D, Tang N. Difference of coagulation features between severe pneumonia induced by SARS-CoV2 and non-SARS-CoV2. J Thromb Thrombolysis 2020; 3; 1-4.

14. Tang N, Bai H, Chen X, Gong J, Li D, Sun Z. Anticoagulant treatment is associated with decreased mortality in severe coronavirus disease 2019 patients with coagulopathy. J Thromb Haemost 2020; 18 (5): 1094-1099. DOI: 10.1111 jth.14817.

15. Menter T, Haslbauer JD, Nienhold R, Savic S, Hopfer H, Deigendesch N, Frank S, Turek D, Willi N, Pargger H, Bassetti S, Leuppi JD, Cathomas G, Tolnay M, Mertz KD, Tzankov A. Post-mortem examination of COVID19 patients reveals diffuse alveolar damage with severe capillary congestion and variegated findings of lungs and other organs suggesting vascular dysfunction. Histopathology 2020. DOI: 10.1111/his.14134.

16. Wichmann D, Sperhake JP, Lütgehetmann M, Steurer S, Edler C, Heinemann A, Heinrich F, Mushumba H, Kniep I, Schröder AS, Burdelski C, de Heer G, Nierhaus A, Frings D, Pfefferle S, Becker H, Bredereke-Wiedling H, de Weerth A, Paschen HR, Sheikhzadeh-Eggers S, Stang A, Schmiedel S, Bokemeyer C, Addo MM, Aepfelbacher M, Püschel K, Kluge S. Autopsy Findings and Venous Thromboembolism in Patients With COVID-19: A Prospective Cohort Study. Ann Intern Med 2020; M20-2003. DOI: 10.7326/M20-2003.

17. Thachil J, Wada H, Gando S, Falanga A, Cattaneo M, Levi M, Clark C, Iba T. ISTH interim guidance on recognition and management of coagulopathy in COVID-19. J Thromb Haemost 2020; 18 (5): 1023-1026. DOI: $10.1111 /$ jth. 14810 .

18. Clinical management of COVID-19. Interim guidance. https: //www. who.int/publications/i/item/clinical-management-of-coVID-19

19. Schulman S, Kearon C. Subcommittee on Control of Anticoagulation of the Scientific and Standardization Committee of the International Society on Thrombosis and Haemostasis. Definition of major bleeding in clinical investigations of antihemostatic medicinal products in non-surgical patients. J Thromb Haemost 2005; 3: 692-694.

20. Rosenbaum PR, Rubin DB. The central role of the propensity score in observational studies for causal effects. Biometrika 1983; 70: 41-55.

21. PattanayakCW,Rubin DB,ZellER.Propensity score methods for creating covariate balance in observational studies. Rev Esp Cardiol 2011; 64: 897-903.

22. Mucha SR, Dugar S, McCrae K, Joseph DE, Bartholomew J, Sacha G, Militello M. Coagulopathy in COVID-19. Cleve Clin J Med 2020 May 14. DOI: $10.3949 /$ ccjm. 87 a.ccc024.

23. Tang N, Li D, Wang X, Sun Z. Abnormal coagulation parameters are associated with poor prognosis in patients with novel coronavirus pneumonia. J Thromb Haemost 2020; 18 (4): 844-847.

24. Fan BE, Chong VCL, Chan SSW, Lim GH, Lim KGE, Tan GB, Mucheli SS, Kuperan P, Onget KH. Hematologic parameters in patients with COVID-19 infection. Am J Hematol 2020; 95 (6): E131-E134.
25. Galván Casas C, Català A, Carretero Hernández G, RodríguezJiménez P, Fernández Nieto D, Rodríguez-Villa Lario A, Navarro Fernández I, Ruiz-Villaverde R, Falkenhain-Lopez D, Llamas Velasco M, García-Gavín J, Baniandrés O, González-Cruz C, Morillas-Lahuerta V, Cubiró X, Figueras Nart I, Selda-Enriquez G, Romaní J, Fustà-Novell X, Melian-Olivera A, Roncero Riesco M, Burgos-Blasco P, Sola Ortigosa J, Feito Rodriguez M, García-Doval I. Classification of the cutaneous manifestations of COVID-19: a rapid prospective nationwide consensus study in Spain with 375 cases. Br J Dermatol 2020. DOI: $10.1111 /$ bjd.19163.

26. Ren B, Yan F, Deng Z, Zhang S, Xiao L, Wu M, Cai L. Extremely High Incidence of Lower Extremity Deep Venous Thrombosis in $48 \mathrm{~Pa}-$ tients with Severe COVID-19 in Wuhan. Circulation 2020. DOI: 10.1161/ CIRCULATIONAHA.120.047407.

27. Guan WJ, Ni ZY, Hu Y, Liang WH, Ou CQ, He JX, Liu L, Shan H, Lei CL, Hui DSC, Du B, Li LJ, Zeng G, Yuen KY, Chen RC, Tang CL, Wang T, Chen PY, Xiang J, Li SY, Wang JL, Liang ZJ, Peng YX, Wei L, Liu Y, Hu YH, Peng P,Wang JM, Liu JY, Chen Z, Li G, Zheng ZJ, Qiu SQ, Luo J, Ye CJ, Zhu SY, Zhong NS. China Medical Treatment Expert Group for CoVID-19 Clinical characteristics of coronavirus disease 2019 in China. N Engl J Med 2020; 382: 1708-1720.

28. Lax SF, Skok K, Zechner P, Kessler HH, Kaufmann N, Koelblinger C, Vander K, Bargfrieder U, Trauner M. Pulmonary Arterial Thrombosis in COVID-19 With Fatal Outcome: Results from a Prospective, SingleCenter, Clinicopathologic Case Series. Annals of Internal Medicine 2020. DOI: $0.7326 / \mathrm{M} 20-2566$.

29. Panigada M, Bottino N, Tagliabue $P$, Grasselli G, Novembrino C, Chantarangkul V, Pesenti A, Peyvandi F, Tripodi A. Hypercoagulability of COVID-19 patients in Intensive Care Unit. A Report of Thromboelastography Findings and other Parameters of Hemostasis. J Thromb Haemost 2020. DOI: $10.1111 /$ jth. 14850 .

30. Llitjos JF, Leclerc M, Chochois C, Monsallier JM, Ramakers M, Auvray M, Merouani K. High Incidence of Venous Thromboembolic Events in Anticoagulated Severe COVID-19 Patients. J Thromb Haemost 2020. DOI: $10.1111 /$ JTH.14869.

31. Mestres G, Puigmacià R, Blanco C, Yugueros X, Esturrica M, Riambau V. Risk of peripheral arterial thrombosis in COVID-19. J Vasc Surg 2020; S0741-5214 (20) 31074-0. DOI: 10.1016/j.jvs.2020.04.477

32. Januzzi JL. Troponin and BNP use in COVID-19. Cardiology Magazine: Amer Coll Cardiol 2020.

33. Paranjpe I, Fuster V, Lala A, Russak A, Glicksberg BJ, Levin MA, Charney AW, Narula J, Fayad ZA, Bagiella E, Zhao S, Nadkarni GN. Association of Treatment Dose Anticoagulation with In-Hospital Survival Among Hospitalized Patients with COVID-19. J Amer Coll Cardiol 2020; S0735-1097 (20): 35218-9. DOI: 10.1016/j.jacc.2020.05.001.

34. Cattaneo M, Bertinato EM, Birocchi S, Brizio C, Malavolta D, Manzoni M, Muscarella G, Orlandi M. Pulmonary Embolism or Pulmonary Thrombosis in COVID-19? Is the Recommendation to Use HighDose Heparin for Thromboprophylaxis Justified? Thromb Haemost 2020. DOI: $10.1055 / \mathrm{s}-0040-1712097$. 